\title{
Metode Service Quality (Servqual) dan Quality Function Deployment (QFD) sebagai Usulan Perbaikan Kualitas Pelayanan di PT. Kereta Api Indonesia (Persero) (Survei pada Penumpang Kereta Ekonomi Lokal Lintas Barat Tahun 2017)
}

\author{
Solehatin Ika Putri ${ }^{1}$, Sumartini ${ }^{2}$, Alifira Sofia ${ }^{3}$ \\ Mahasiswa Magister Manajemen Bisnis \\ Sekolah Pasca Sarjana Universitas Pendidikan Indonesia
}

\begin{abstract}
Abstrak
Tujuan penelitian ini adalah untuk mengetahui gambaran tingkat kualitas pelayanan Kereta Ekonomi Lokal Lintas Barat, dan mengetahui indikator yang dapat menggambarkan dimensi kualitas pelayanan serta merancang usulan perbaikan kualitas pelayanan di PT. KAI (Persero).

Metode Service Quality (Servqual) melalui 5 dimensinya digunakan untuk mengetahui tingkat kualitas pelayanan. Analisis faktor digunakan untuk menentukan indikator penentu dilanjutkan dengan Importance Performance Analysis (IPA) untuk mencari faktor prioritas. Rancangan perbaikan diusulkan setelah melakukan analisis dengan Quality Function Deployment (QFD). Kuesioner disebarkan pada 393 penumpang Kereta Ekonomi Lokal Lintas Barat dengan teknik convenience sampling. Kualitas pelayanan Kereta Api Ekonomi Lokal Lintas Barat termasuk pada tingkatan sedang yang menunjukkan belum terpenuhinya kualitas yang diharapkan pelanggan. Terdapat 21 indikator yang dapat menggambarkan dimensi kualitas pelayanan dengan indikator terkait kesiapan petugas dalam mengarahkan tangga bantuan dari peron ke pintu kereta yang memiliki tingkat ketidakpuasan tertinggi. Usulan perbaikan yang menjadi prioritas berdasarkan hasil analisis QFD yaitu meningkatkan pengawasan pelaksanaan SOP dari para petugas.
\end{abstract}

Kata Kunci: Service Quality, Quality Function Deployment, Analisis Faktor, Importance Performance Analysis (IPA)

\section{PENDAHULUAN}

Jenis transportasi yang termasuk kedalam indikator ekonomi dalam Buletin Statistik Bulanan BPS (2016, hlm. 141) antara lain angkutan darat (berupa Kereta Api), angkutan laut dan angkutan udara. Jenis transportasi di Indonesia dengan jumlah pengguna terbanyak yaitu jenis angkutan darat seperti yang disajikan dalam tabel 1.1. Sehingga penilaian pelaksanaan jasa transportasi di Indonesia secara menyeluruh menurut I Gede (2015, hlm. 536) dapat diwakili oleh penilaian transportasi umum darat.

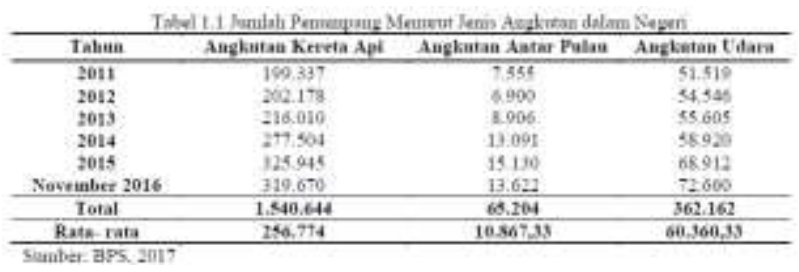

Berdasarkan tabel tersebut, angkutan darat berupa Kereta Api paling banyak digunakan masyarakat untuk mengakses tempat tujuan. Kereta Api menjadi pilihan karena angkutan ini dapat mengangkut penumpang secara masal, nyaman, biaya yang terjangkau oleh berbagai lapisan masyarakat dan terhindar dari kemacetan karena memiliki jalur sendiri. Hal ini sejalan dengan 4 empat pilar utama layanan PT. KAl Persero berdasarkan Annual Report (2015, hlm. 103) yaitu fokus pada keselamatan, ketepatan waktu, pelayanan dan kenyamanan pengguna jasa.

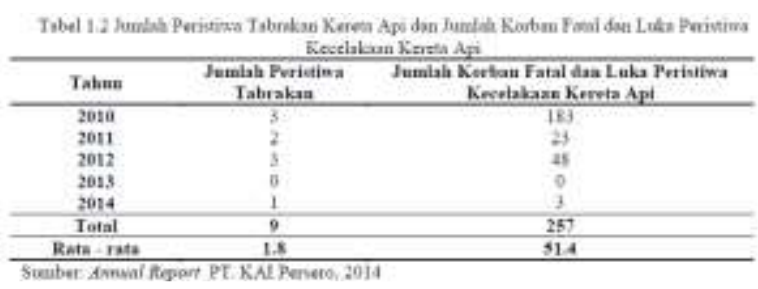


Berdasarkan tabel 1.2 dapat dilihat angka jumlah peristiwa tabrakan Kereta Api, jumlah korban fatal dan luka menurun di tahun 2011, akan tetapi meningkat kembali pada tahun 2012. Walaupun pada tahun 2013 jumlahnya nol, namun pada tahun 2014 jumlahnya kembali meningkat. Adapun untuk Kereta Patas Merak dan Lokal Rangkas terus mengalami penurunan jumlah penumpang dari tahun 2012 sampai 2016. Berikut ini rata - rata volume penumpang Kereta Ekonomi Lokal Lintas Barat non komersil.

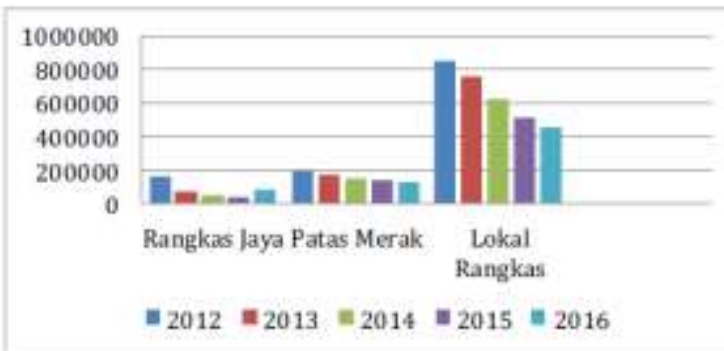

Gambar 1.2 Rata - rata Volume Penumpang Kereta Ekonomi Lokal Lintas Barat Non Komersil 2012 s.d 2016

Sumber: Humas PT. KAI Persero yang diolah, 2017

Penurunan jumlah penumpang Kereta Ekonomi Lokal Lintas Barat non komersil diduga karena beralihnya calon penumpang ke moda transportasi lain, selain karena terdapat beberapa keluhan terkait pelayanan Kereta Ekonomi Lokal Lintas Barat yaitu pada tanggal 6 April 2015 terjadi pemblokiran jalur Kereta oleh calon penumpang di Stasiun Cikoya terkait perubahan kebijakan oleh PT. KAI Persero DAOP I mengenai pemberhentian di beberapa stasiun yang berdampak pada terganggunya perjalanan Kereta Api yaitu pemberangkatan dari Stasiun Merak, Serang dan Rangkasbitung menuju Jakarta. Dengan demikian PT. KAI Persero akan fokus pada indikator yang menjadi prioritas perbaikan, sesuai dengan pendapat Vinayak dan Rambabu (2013, hlm. 825) bahwa QFD merupakan alat yang dapat membantu perusahaan untuk fokus terhadap apa yang dirasakan dan diinginkan oleh konsumen dari produk atau jasa yang dihasilkan.

\section{KERANGKA PENELITIAN \& HIPOTESIS}

Heizer dan Render (2015, hlm. 248) Total Quality Management (TQM) merupakan kesatuan antara seluruh pihak dalam organisasi dan pelanggan dalam hal kualitas. TQM memiliki 10 unsur utama menurut Goetsch dan Davis (1994: 14-18) dalam Nasution (2015, hlm. 18). Parasuraman, Zeithmal dan Berry (1985, hlm. 40 dan 44) menyatakan bahwa jasa merupakan barang intangible hasil dari suatu jasa tergantung dari objek yang menggunakannya. Intinya, perusahaan jasa tidak mungkin selalu mengerti apa ciri - ciri dari kualitas yang tinggi untuk menarik konsumen, ciri - ciri pelayanan apa yang dapat memenuhi kebutuhan konsumen dan level kinerja apa yang dibutuhkan untuk memberikan kualitas pelayanan yang tinggi.

Heizer dan Render (2015, hlm. 262) menyatakan bahwa kualitas jasa dinilai dari sejauh mana pelayanan yang diberikan dapat memenuhi ekspektasi atau dengan kata lain persepsi pelanggan terhadap kualitas jasa didapat dari perbandingan antara ekspektasi sebelum jasa diperoleh dengan ekspetasi aktual jasa yang dirasakan. Parasuraman, Zeithmal dan Berry (1985, hlm. 42)

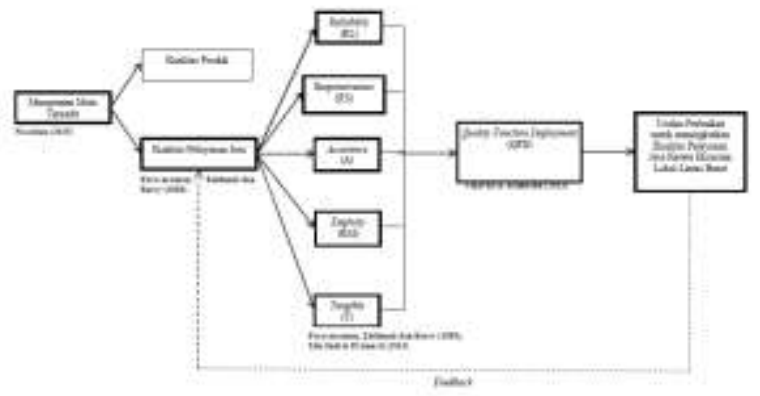

Kerangka Pemikiran Metode Service Quality (Servqual) dan Quality Function Deployment (QFD) sebagai Usulan Perbaikan Kualitas Pelayanan di PT. Kereta Api Indonesia (Persero)

Hipotesis 1 : Reliability dapat digambarkan melalui indikator RL1, RL2, RL3 dan RL4.

Hipotesis 2 : Responsiveness dapat digambarkan melalui indikator RS5, RS6, RS7, RS8, dan RS9.

Hipotesis 3 : Assurance dapat digambarkan melalui indikator A10, A11, A12, A13, A14, dan A15. 
Hipotesis 4 : Emphaty dapat digambarkan melalui indikator EM16, EM17, EM18, EM19, dan EM20.

Hipotesis 5 : Tangible dapat digambarkan melalui indikator T21, T22, T23, T24, T25, T26, T27, T28, dan T29.

\section{METODE PENELITIAN}

Objek dalam penelitian ini adalah kualitas pelayanan Kereta Api Ekonomi Lokal Lintas Barat DAOP 1 Jakarta dengan 5 dimensi kualitas pelayanan dengan 29 indikator yaitu reliability 4 indikator, responsiveness 5 indikator, assurance 6 indikator, emphaty 5 indikator, dan tangible 9 indikator. Metode SERVQUAL, analisis

\section{KESIMPULAN}

1. Tingkat kualitas pelayanan Kereta Api Ekonomi Lokal Lintas Barat menurut persepsi penumpang belum memenuhi harapan kualitas yang diinginkan dan belum mampu memuaskan pelanggan. Kesiapan petugas dalam mengarahkan tangga bantuan dari peron ke pintu kereta dan aspek daya tanggap dalam memberikan pelayanan kepada penumpang merupakan hal dengan tingkat ketidakpuasan tertinggi.

2. Terdapat 21 indikator yang dapat menggambarkan kelima dimensi kualitas pelayanan. Reliability (keandalan) digambarkan oleh 2 indikator, responsiveness (daya tanggap) digambarkan oleh 5 indikator, assurance (jaminan kepastian) digambarkan melalui 4 indikator, empathy (empati) digambarkan melalui 3 indikator dan tangible (bukti fisik) digambarkan oleh 7 indikator.

3. Usulan perbaikan berdasarkan 8 kemampuan teknis untuk menjawab 6 indikator yang menjadi prioritas perbaikan yaitu dengan meningkatkan sistem pengawasan dan pelaksanaan Standard Operating Procedure (SOP) dari para petugas, standarisasi kebutuhan petugas teknis dan pendukung, tingkat responsif petugas, jumlah petugas teknis dan pendukung, perbaikan sound speaker, kemudahan akses aplikasi portal PT. KAl untuk kereta ekonomi, pengecekan tim kebersihan, dan kemampuan masinis dan tim untuk tepat waktu. faktor serta metode Importance Performance Analysis (IPA) digunakan untuk mengetahui preferensi utama dari ke lima dimensi kualitas pelayanan, kemudian penggunaan metode Quality Function Deployment (QFD) dengan House of Quality (HoQ) dilakukan untuk menghasilkan usulan perbaikan kualitas pelayanan.

Analisis faktor dilakukan dengan tujuan untuk mengetahui indikator mana yang dapat menggambarkan masing-masing variabel laten/konstruk dalam pengukuran kualitas pelayanan dari ke 28 indikator. Hasil kuesioner yang diberikan kepada penumpang KA Ekonomi Lokal Lintas Barat akan diolah dengan pengujian model pengukuran CFA. 4. HASIL DAN PEMBAHASAN

Tabel 4.12 Persamaan Pengukuran Kualitas Pelayanan Jasa

\begin{tabular}{|c|c|c|c|}
\hline Model Pengukuran & Indikator & Persama & in Pengukuran \\
\hline \multirow{4}{*}{ Reliability (RL) } & RL1 & RL1 & $=\lambda_{1} R L+e_{1}$ \\
\hline & RL2 & RL2 & $=\lambda_{2} R L+e_{2}$ \\
\hline & RL3 & RL3 & $=\lambda_{3} R L+e_{3}$ \\
\hline & RL4 & RL4 & $=\lambda_{4} R L+e_{4}$ \\
\hline \multirow{5}{*}{ Responsiveness (RS) } & RS5 & RS5 & $=\lambda_{3} R S+e_{5}$ \\
\hline & RS6 & RS6 & $=\lambda_{6} \mathrm{RS}+\mathrm{e}_{6}$ \\
\hline & RS7 & RS7 & $=\lambda_{7} \mathrm{RS}+\mathrm{e}_{7}$ \\
\hline & RS8 & RS8 & $=\lambda_{8} \mathrm{RS}+\mathrm{e}_{8}$ \\
\hline & RS9 & RS9 & $=\lambda_{9} \mathrm{RS}+e_{9}$ \\
\hline \multirow{5}{*}{ Model Pelagokicuran } & Indikator & \multicolumn{2}{|c|}{ Percamaan Penzukauran } \\
\hline & EMI? & \multicolumn{2}{|c|}{$\mathrm{EMI} 7=\lambda_{17} \mathrm{EM}+e_{i 9}$} \\
\hline & EMI8 & \multicolumn{2}{|c|}{$E M 1 s=\lambda_{n} E M-n_{1}$} \\
\hline & EM19 & \multicolumn{2}{|c|}{ EM19-20EM- 19} \\
\hline & EMP0 & \multicolumn{2}{|c|}{$\mathrm{EM} 20-3{ }_{20} \mathrm{EM}+\mathrm{C}_{20}$} \\
\hline \multirow{8}{*}{ Tangibed (T) } & $\mathrm{T21}$ & T21 & $-3 \mathrm{~T} T+e_{41}$ \\
\hline & T23 & T23 & $-k_{n} \mathrm{~T}+\mathrm{t}_{1 y}$ \\
\hline & T24 & $\mathrm{T} 24$ & $=\lambda_{20} T+e_{x}$ \\
\hline & T25 & T2S & $=\lambda_{25} T+e_{25}$ \\
\hline & $\mathrm{T} 26$ & T26 & $-\lambda_{a s} \mathrm{~T}+\mathrm{ex}_{x}$ \\
\hline & $\mathrm{r} 27$ & T27 & $-\lambda_{2 y} \mathrm{~T}+e_{2}$ \\
\hline & $\mathrm{T} 28$ & $\mathrm{~T} 28$ & $=\lambda_{m} T+e_{i x}$ \\
\hline & T29 & T29 & $=2, T+e y$ \\
\hline
\end{tabular}

Berdasarkan gambar 4.1 diperoleh hasil uji kesesuaian model dari 5 dimensi kualitas pelayanan jasa dengan 28 indikator. Dengan melihat nilai loading faktor dari masing-masing indikator dan syarat ukuran GFT. Model kualitas pelayanan jasa tidak fit dengan data karena memiliki nilai $(P=0,000<0,05$; RMSEA = $0,115>0,08 ; \mathrm{CFI}=0,660<0,90)$. Artinya model tidak mampu mengestimasi matriks kovariansi populasi $(\Sigma)$ yang tidak berbeda dengan matriks kovariansi sampel (S). Adapun nilai bobot faktor masing-masing indikator dapat dilihat pada tabel 4.13 sebagai berikut.

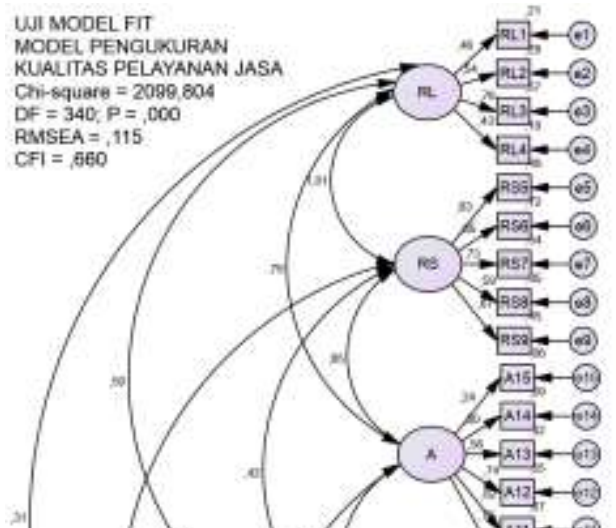


Gambar 4.1

Overall Measurement Model Kualitas Pelayanan Jasa

\section{(Standardized Estimates)}

Setelah diperbaiki dan di uji ulang overall measurement model kualitas pelayanan jasa fit dengan data. Walaupun nilai $P$ - hitung sebesar 0,000 kurang dari 0,05 dan nilai RMSEA sebesar 0,082 masih lebih besar dari 0,08 namun nilai $\mathrm{CFI}=0,913>0,90$ nilainya sudah sesuai dengan yang di standarkan. Selain itu koefisien bobot faktor secara statistik seluruhnya signifikan ( $\mathrm{P}$-value $<0,05$ ) dengan nilai estimasi standardized seluruhnya $>0,50$.

\section{REKOMENDASI}

Daya tanggap dan keandalan dalam memberikan pelayanan kepada penumpang merupakan hal terpenting yang perlu lebih diperhatikan dan diperbaiki oleh PT. KAI (Persero).

Dua puluh satu indikator yang dapat menggambarkan kualitas pelayanan Kereta Ekonomi Lokal Lintas Barat dapat menjadi preferensi dalam menentukan kebijakan perbaikan kualitas pelayanan dengan memprioritaskan 6 hal yang dianggap sangat penting bagi penumpang dengan kondisi pelayanan yang dirasakan masih kurang.

Perbaikan kualitas pelayanan Kereta Ekonomi Lokal Lintas Barat dapat dilakukan oleh PT. KAI
(Persero) khususnya DAOP I dengan terlebih dahulu fokus pada sistem pengawasan dalam pelaksanaan SOP perusahaan

\section{DAFTAR PUSTAKA}

A. Parasuraman (2004). Assessing and Improving Service Performance for Maximum Impact: Insights from A Two-Decade-Long Research Journey. Performance Measurement and Metrics, Vol. 5 Iss 2 pp. 45 - 52.

Andini, Seno Adi. (2005). Analisa Kualitas Layanan Bandar Udara Juanda dengan Menggunakan Metode QFD. Prosiding Seminar Nasional Manajemen Teknologi I. Program Studi Magister Manajemen Teknologi, Institut Teknologi Sepuluh Nopember. Surabaya.

Annual Report PT. Kereta Api (Persero) tahun 2014. http://kereta-

api.co.id/media/document/annual_report_2014 .pdf diakses 9/26/2016 pukul 11.55 WIB

Annual Report PT. Kereta Api (Persero) tahun 2015. http://kereta-

api.co.id/media/document/annual_report_2015 .pdf diakses 9/26/2016 pukul 15.02WIB

Assauri. Sofyan. (2016). Manajemen Operasi dan Produksi. PT. Rajagrafindo Persada: Jakarta.

Awasthi, Anjali dkk. (2011). A Hybrid Approach Based on SERVQUAL and Fuzzy TOPSIS for Evaluating Transportation Service Quality. Journal of Computers \& Industrial Engineering 61 (2011) 637-646.

Banten Dalam Angka 2016. https://www.bps.go.id/website/pdf_publikasi/B anten-Dalam-Angka-2016.pdf diakses 29/03/2017 pukul 19.05 WIB

Budi Waryanto, Yuan Astika Millafati, (2006). The Transformation of Ordinal Data to Interval Data 
Using Makro Minitab. Informatika Pertanian Volume 15, 2006 881-895.

Buletin Statistik Bulanan Indikator Ekonomi BPS November 2016. https://www.bps.go.id/website/pdf_publikasi// ndikator-Ekonomi-November-2016.pdf diakses 01/10/2017 pukul 08.05 WIB

Camgöz-Akdağ,Hatice dkk . (2016). Internal Customer Satisfaction Improvement with QFD Technique. Business Process Management Journal. Vol. 22 Iss 5 pp. $957-968$.

Chowdhury, Hossan dan Mohammed (2016). A multiphased QFD based optimization approach to sustainable service design, Int. J.ProductionEconomics171(2016)165-178.

Garver, Michael S. (2012),"Improving the house of quality with maximum difference scaling", International Journal of Quality \& Reliability Management, Vol. 29 Iss 5 pp. 576 - 594

Gregorio, Ruben dan Peter Cronemyr, (2011),"From expectations and needs of service customers to control chart specification limits", The TQM Journal, Vol. 23 Iss 2 pp. $164-178$.

Hadi Akbarzade Khorshidi dan Seyed Reza Hejazi(2011). Optimising service quality translating via quantitative quality function deployment. Int. J. Services and Standards, Vol. 7, No. 2, 2011

Haming. Murdifin dan Mahfud Nurnajamuddin. (2007). Manajemen Produksi Modern Operasi Manufaktur dan Jasa Buku 2. Bumi Aksara: Jakarta.

Haryono, Siswoyo. (2017). Metode SEM untuk Penelitian Manajemen dengan AMOS LISREL PLS. Luxima: Jakarta.

Hasti Purnasari, dkk. (2012) Evaluasi Layanan Pelanggan Berbasis Quality Function Deployment (QFD). Studi Kasus: PT. Mitra Nasional Kualitas. e- jurnal agroindustry. Vol 1 No.2, Oktober 2012, p 88-94, ISSN: 2252-3324
Heizer. Jay dan Barry Render. (2015). Manajemen Operasi: Manajemen Keberlangsungan dan Rantai Pasok. Salemba Empat: Jakarta.

Hsu, Wen-Kai K. (2013). Improving the Service Operations of Container Terminals. The International Journal of Logistics Management, Vol. 24 Iss 1 pp. 101 - 116

http://metro.tempo.co/read/news/2009/02/27/0831 62359/anjloknya-kereta-jakarta-merakternyata-akibat-karung-petugas diakses 01/10/2017 pukul 08.15 WIB

http://print.kompas.com/baca/metropolitan/2015/0 4/06/jalur-diblokir\%2c-perjalanan-kereta-apimerak-serang diakses 01/10/2017 pukul 08.10 WIB

I Gede Mahatma Yuda Bakti Sik Sumaedi. (2015). PTRANSQUAL: a Service Quality Model of Publicland Transport Services. International Journal of Quality \& Reliability Management. Vol. 32 Iss 6 pp. $534-558$.

lqbal, Zafar dkk. (2014),"Statistical comparison of final weight scores in quality function deployment (QFD) studies", International Journal of Quality \& Reliability Management, Vol. 31 Iss 2 pp. 184 204

Jalur diblokir, perjalanan kereta api Merak - Serang Rangkasbitung - Jakarta terganggu. (2015).

Khorshidi dkk. (2016). Statistical Process Control Application on Service Quality using SERVQUAL and QFD with a Case Study in Trains' Services. The TQM Journal, Vol. 28 Iss 2 pp. $195-215$.

Kotler. Philip and Kevin Lane Keller. (2012). Marketing Management Fourteenth. United States of America: Pearson Education.

Kusnendi. (2008). Model - model Persamaan Struktural: Satu \& Multigroup Sample dengan LISREL. Alfabeta: Bandung.

Lithrone Laricha dkk. (2015). Pengaruh Dimensi Kualitas terhadap Kepuasan Pelanggan Dunia Fantasi PT. PJA. Jurnal Ilmiah Teknik Industri (2015), Vol. 3 No. 1, $25-32$. 
Matius J Situmorang. dkk. (2013). Pendekatan Metode Quality Function Deployment (QFD). e-Jurnal Teknik Industri FT USU Vol 4. No. 1. Oktober 2013 pp. $6-12$.

Mehrjerdi, Yahia Zare (2010),"Quality function deployment and its extensions", International Journal of Quality \& Reliability Management, Vol. 27 Iss 6 pp. $616-640$

Moda Transportasi Darat 2011 - 2015. https://www.bps.go.id/website/pdf_publikasi/T ransportasi-Darat-2011-2015.pdf diakses 29/03/2017 pukul 19.30 WIB

Morton, Craig dkk. (2016). Customer Perceptions of Quality of Service in Public Transport: Evidence for bus transit in Scotland. Case Studies on Transport Policy http://dx.doi.org/10.1016/j.cstp.2016.03.002

Nasution, Nur. (2015). Manajemen Mutu Terpadu (Total Quality Management). Ghalia Indonesia: Bogor.

Semchugova, Elena dkk. (2017). Models of Estimation of Application of Passenger Service Quality Parameters. Journal of Transportation Research Procedia 20 ( 2017 ) $584-590$.

Siregar. Syofian. (2014). Statistic Parametrik untuk Penelitian Kuantitatif. Bumi Aksara: Jakarta.

Sustainability Report PT. Kereta Api (Persero) tahun 2014. http://keretaapi.co.id/media/document/sustainability_repor t_2014.pdf diakses 9/26/2016 pukul 15.50 WIB

Sustainability Report PT. Kereta Api (Persero) tahun 2015. http://keretaapi.co.id/media/document/sustainability_repor t_2015.pdf diakses 9/26/2016 pukul 15.55 WIB

Tjiptono, Fandi. (2008). Service Management: Mewujudkan Layanan Prima. Andi Offset: Yogyakarta.

Vinayak, Kalluri dan Rambabu Kodali. (2013). Benchmarking the Quality Function Deployment
Models, Benchmarking: An International Journal, Vol. 20 Iss 6 pp. $825-854$.

Widodo, Yudi dan Zulfa Fitri. (2014). Implementasi Metode Quality Function Deployment Untuk Meningkatkan Kualitas Produk Lift. Jurnal IImiah Teknik Industri Vol. 2 No. 3, 195 - 203. 